\title{
Analisis Sistem Keuntungan Pola Bagi Hasil Nelayan Kelong Apung Pulau Pucung Desa Malang Rapat Kabupaten Bintan
}

\author{
Myrna Sofia, Inge Lengga Sari Munthe
}

Fakultas Ekonomi Universitas Maritim Raja Ali Haji, Tanjungpinang, Kepulauan Riau, Indonesia

\begin{abstract}
ABSTRAK : Pemerintah daerah Kabupaten Bintan dalam hal ini Dinas Kelautan dan Perikanan telah mengalokasikan dana dalam bentuk sarana dan prasarana alat tangkap ikan termasuk kelong. Upaya pemerintah kabupaten Bintan melalui dinas Kelautan dan Perikanan telah melakukan upaya untuk meningkatkan kesejahteraan nelayan yang ada di Kabupaten Bintan, tetapi apakah upaya tersebut telah dirasakan langsung oleh nelayan di pulau Pucung Desa Malang Rapat Kabupaten Bintan. Di mana mayoritas nelayan di pesisir pantai Kabupaten Bintan menggunakan Alat Tangkap Kelong Apung. Penelitian ini bertujuan untuk mengetahui pola keuntungan bagi hasil antara pemilik kelong "Toke" dengan nelayan buruh kelong apung di pulau Pucung Desa Malang Rapat Kabupaten Bintan. Dan melakukan perbandingan antara pola bagi hasil yang diterapkan oleh pemilik kelong.. Penelitian dilakukan dengan menggunakan data primer yang diperoleh langsung dari nelayan dalam bentuk laporan harian. Penelitian dilakukan selama 4 (empat) bulan dari bulan April sampai dengan bulan Juli tahun 2018. Jumlah Responden dalam penelitian sebanyak 78 orang. Nelayan pulau pucung menerapkan 3 pola bagi hasil untuk kegiatan tangkap ikan dengan menggunakan kelong apung yaitu : System Gaji, 1:1 dan 2:1.
\end{abstract}

Kata Kunci : Nelayan, Kelong Apung, Pola Keuntungan Bagi Hasil

ABSTRACT : The local government of Bintan Regency in this case the Department of Marine and Fisheries has allocated funds in the form of fishing gear facilities and infrastructure including kelong. The efforts of the Bintan district government through the Ministry of Marine Affairs and Fisheries have made efforts to improve the welfare of fishermen in Bintan Regency, but whether these efforts have been directly felt by fishermen on the island of Pucung, Malang Village, Bintan District Meeting. Where the majority of fishermen on the coast of Bintan Regency use the Floating Kelong Fishing Equipment. This study aims to determine the profit sharing pattern between kelong owners "Toke" with floating kelong fishermen on Pucung Island Malang Village Bintan District Meeting.. The research was conducted using primary data obtained directly from fishermen in the form of daily reports. The study was conducted for 4 (four) months from April to July 2018. The number of respondents in the study were 78 people. Pucung Island fishermen apply 3 profit sharing patterns for fishing activities using floating kelong, namely: Salary System, 1: 1 and 2: 1 .

Keywords: Fishermen, Kelong Apung, Patterns of Profit for Results

Email Address : myrnasofia@umrah.ac.id 


\section{Pendahuluan}

Kabupaten Bintan memiliki 8 Desa salah satunya adalah desa Malang Rapat, yang secara historis, dahulu desa Malang Rapat berada di wilayah kecamatan Bintan Timur Kabupaten Kepulauan Riau, tetapi setelah otonomi dan pemekaran wilayah desa Malang Rapat termasuk dalam wilayah Kecamatan Gunung Kijang Kabupaten Bintan.

Pada tahun 2017 dinas DKP Bintan telah mengalokasi dana dari APBD sebesar Rp. 5,5 miliar. Dana tersebut digunakan untuk membantu aktivitas nelayan dalam meningkatkan kesejahteraan taraf hidupnya. Dana tersebut digunakan untuk pengadaan pembelian empat unit kapal berbahan kayu berkapasitas lima Gross Tone (GT), tujuh unit kapal berbahan kayu dan fiber berkapasitas satu GT, kelong apung sebanyak sembilan unit dan berbagai jenis alat tangkap ikan di sembilan kecamatan. Semua bantuan tersebut diserahkan ke kelompok nelayan. Dengan bantuan tersebut hasil tangkapan ikan bertambah banyak, dengan begitu keuntungan juga melonjak sehingga kesejahteraan hidup juga akan terus meningkat.

Meskipun terjadi peningkatan hasil tangkapan ikan dari tahun ke tahun di kabupaten Bintan, secara umum penghasilan nelayan mengalami peningkatan.Tetapi apakah peningkatan penghasilan nelayan tersebut telah mengindikasikan bahwa tingkat kesejahteraan nelayan mengalami peningkatan khususnya pada nelayan kelong apung yang bekerja dengan toke sebagai nelayan buruh. Hal ini penting untuk dilakukan karena nelayan buruh merupakan masyarakat pesisir yang banyak dikenal bahwa tingkat kemiskinan mereka harus menjadi perhatian oleh pemerintah. Sementara Nelayan buruh kelong masih bergantung pada Toke, karena meskipun ada bantuan dari pemerintah daerah misalnya berupa kelong tetapi ketersediaan solar dan jaminan hidup keluarga masih mengandalkan peran toke. Nelayan buruh tidak bisa melepaskan diri dari toke, karena untuk melaut harus ada pompong, solar untuk penerangan kelong, logistik makanan, uang rokok sampai dengan belanja untuk anak istri. Semua kebutuhan itu bisa diperoleh melalui toke.

Kemudian antara toke dan nelayan buruh yang menggunakan alat tangkap kelong apung terkait pembagian keuntungan bagi hasil, toke menerapkan beberapa pola pembagian hasil keuntungan. Ada beberapa pola pembagian hasil keuntungan tersebut diantaranya pola bagi 2 yaitu dengan perbandingan 1:1 atau pola bagi tiga yaitu dengan perbandingan 2:1, dan ada juga yang menerapkan system gaji, sehingga berdampak kepada tingkat penghasilan, keadilan yang akan meningkatkan kesejahteraan nelayan tersebut.

Toke kelong atau lebih dikenal sebagai pemilik kelong di Pulau Pucung memiliki beberapa kategori, antara lain ada pemilik kelong yang ikut melaut dan ada juga yang tidak melaut, jika pemilik kelong ikut melaut pembagian hasil antara pemilik kelong dengan nelayan buruh yang dalam hal ini adalah anak buah kapal (ABK) ada yang menggunakan system gaji dan bagi hasil, jika pemilik kelong tidak ikut melaut pembagian hasil antara pemilik kelong dengan tekong adalah 1:1, dan pembagian antara tekong dengan $\mathrm{ABK}$ ada yang bagi hasil sebesar 2:1 dan ada juga yang menerapkan system gaji, dimana gaji tersebut dimasukan ke dalam biaya operasional.

Penelitian tentang pembagian hasil untuk usaha nelayan buruh kelong ini belum pernah dilakukan.

Perumusan masalah dalam penelitian ini adalah

1). Bagaimana pola keuntungan bagi hasil yang diterapkan oleh pemilik kelong pulau Pucung Desa Malang Rapat Kabupaten Bintan? Penelitian ini bertujuan untuk menganalisis bagaimana pola pembagian keuntungan hasil usaha antara toke dengan nelayan buruh.

Adapun manfaat dari penelitian ini adalah:

Pada penelitian ini diharapkan bisa memberikan masukan atau dapat dijadikan sebagai kebijakan pemerintah kabupaten Bintan terkait penetapan pola bagi hasil keuntungan antara pemilik kelong atau toke dengan nelayan 
buruh kelong apung, Dan terciptanya kondisi adil antara toke dengan nelayan buruh.

\section{Metodologi Penelitian}

Masyarakat nelayan merupakan suatu masyarakat yang tinggal di wilayah pesisir dengan mata pencaharian utama adalah memanfaatkan Sumber Daya Alam (SDA) yang terdapat di dalam lautan, baik itu berupa ikan, udang, rumput laut, kerang kerangan, terumbu karang dan hasil kekayaan laut lainnya.

(Kusnadi, 2002) mengatakan bahwa secara geografis masyarakat nelayan adalah masyarakat yang hidup, tumbuh dan berkembang di kawasan pesisir, yakni suatu kawasan transisi antara wilayah darat dan laut.

Menurut statusnya, (Marbun, 2002) membagi kelompok nelayan menjadi tiga bagian:

1. Nelayan pemilik yang dapat dibagi lagi menjadi nelayan pemilik perahu tak bermotor dan nelayan pemilik kapal motor yang disebeut "toke".

2. Nelayan juragan adalah pengemudi para perahu bermotor atau sebagai kapten kapal motor.

3. Nelayan buruh adalah orang yang bertugas sebagai penangkap ikan pada perahu motor yang sering disebut anak buah kapal.

Menurut (Subri, 2005) Nelayan dapat dibedakan menjadi tiga kelompok, yaitu nelayan buruh, nelayan juragan, dan nelayan perorangan.

Kelong merupakan alat tangkap tradisional, yang terbuat dari kayu, dalam pengoperasiannya selama ini, kelong hanya menggunakan cahaya lampu sebagai penarik perhatian ikan.Agar cahaya ini dapat memikat ikan dengan maksimal, maka pengoperasiannya dilakukan dimalam hari. (Suroto, dkk, 2012)

(Evers, 1982) berpendapat bahwa, pendapatan merupakan hasil yang diperoleh masyarakat dalam memenuhi kebutuhan seharihari atau seluruh penerimaan, baik berupa uang maupun barang, yang diperoleh dari pihak lain maupun sendiri. Menurut (Fahrudin, 2012) berpendapat bahwa kesejahteraan merupakan suatu kondisi dimana seseorang mampu memenuhi kubutuhan pokok baik itu kebutuhan akan makanan pakaian tempat tinggal air minum yang bersih dan kesempatan untuk melanjutkan pendidikan dan memiliki pekerjaan yang memadai sehingga menunjang kualitas hidupnya sehingga hidupnya bebas dari kemiskinan kebodohan, ketakutan atau kekhawatiran sehingga hidupnya aman dan tentram.

Karena imbalan merupakan salah satu tujuan yang hendak dicapai oleh seseorang dalam melakukan usahanya. Apakah imbalan yang telah diterima oleh nelayan kelong tersebut telah sesuai dengan beberapa pola sistem bagi hasil dimana menurut Scheltema (1985) sistem bagi hasil dibedakan menjadi beberapa pola. Ada pola bagi dua, pola bagi tiga, pola bagi empat bahkan ada pola bagi lima. Pola bagi hasil di pulau Pucung Kabupaten Bintan ini biasanya menjalankan pola bagi dua (1:1) dan pola bagi tiga (2:1) Pola bagi dua yaitu ketika pemilik dan nelayan menerima bagian yang sama besar (perbandingan keuntungan yang diterima adalah 1:1). Sedangkan pola bagi tiga terjadi jika perbandingan keuntungan yang diterima oleh pemilik dan nelayan adalah 2:1.

Penelitian ini menggunakan metode deskriptif kuantitatif yaitu penggabungan antara penelitian kualitatif dan kuantitatif. Karena selain menggunakan data primer untuk menganalisis data guna mengetahui dan menghitung keuntungan bagi hasil antara nelayan buruh kelong dengan toke

\section{Lokasi dan Waktu Peneltian}

Penelitian dilakukan di Pulau Pucung Desa Malang Rapat Kabupaten Bintan Provinsi Kepulauan Riau. Penelitian dilakukan selama empat bulan terhitung bulan April sampai dengan Juli 2018.

\section{Jenis dan Sumber Data}

Jenis data yang digunakan dalam penelitian ini adalah data primer yang diperoleh langsung dari nelayan kelong apung dengan 
teknik wawancara dan penyebaran kuesioner penelitian. Data juga diperoleh langsung dari Sekreteris Desa Malang Rapat dan Ketua Nelayan Pulau Pucung Desa Malang Rapat.

\section{Metode Sampling}

Populasi pada penelitian ini adalah seluruh nelayan buruh kelong apung pulau Pucung desa Malang Rapat Kabupaten Bintan yang saat ini informasi yang diperoleh berjumlah sekitar 120 kelong.. Dengan metode pengambilan sampel adalah metode purposive sampling, yaitu pengambilan sampel dengan menggunakan beberapa kriteria tertentu: Adapun kriteria yang digunakan adalah sebagai berikut:

a. Nelayan yang dijadikan sampel adalah nelayan yang menggunakan kelong apung bukan cacak

b. Nelayan yang dijadikan sampel adalah toke, tekong maupun ABK kelong apung.

Setelah dilakukan penyebaran kuesioner dan wawancara dengan nelayan diperoleh ada sebanyak 78 responden yang berhasil mengisi kuesioner. Sehingga sample dalam penelitian ini adalah sebanyak 78 orang responden.

\section{Metode Analisis}

Pengolahan data dilakukan dengan menggunakan uji statistik deskriptif SPSS Versi 22.0 for window.

\section{Hasil dan Pembahasan}

\section{Gambaran Umum Responden}

Penelitian ini dilakukan dengan menggunakan metode wawancara dan penyebaran kuesioner/angket kepada nelayan baik pemilik kelong, tekong maupun anak buah kapal (ABK). Berdasarkan hasil wawancara diperoleh bahwa di desa Malang Rapat pemilik kelong ada yang ikut turun melaut dan ada juga yang tidak ikut turun melaut. Jika pemilik kelong yang ikut turun melaut, pemilik kelong dibantu oleh Tekong/ABK, sementara jika pemilik kelong tidak ikut melaut maka pemilik kelong menunjuk satu orang sebagai tekong dan satu orang Anak Buah Kapal (ABK).

Adapun jumlah nelayan yang berhasil diwawancarai sebanyak 78 orang dan sebaran responden dalam penelitian ini adalah sebagai berikut:

Tabel 1. Sebaran Responden

Table 1. Distrubution of Respondent

\begin{tabular}{|l|l|c|}
\hline \multicolumn{1}{|c|}{$\begin{array}{c}\text { No/ } \\
\text { No }\end{array}$} & \multicolumn{1}{|c|}{$\begin{array}{c}\text { Nelayan/ } \\
\text { Fisherman }\end{array}$} & $\begin{array}{c}\text { Jumlah (Orang)/ } \\
\text { Amount People }\end{array}$ \\
\hline 1. & Toke & 7 \\
\hline 2. & Toke dan Tekong & 12 \\
\hline 3. & Tekong & 11 \\
\hline 4. & Anak Buah Kapal & 48 \\
\hline TOTAL & & $\mathbf{7 8}$ \\
\hline
\end{tabular}

Sumber /Source : Data Primer Diolah (2018)/ Primary Data Processed (2018)

Pola Bagi Hasil Nelayan

Sementara sebaran pola bagi hasil antara toke/pemilik kelong dan nelayan buruh adalah dengan menggunakan system gaji, pola bagi hasil 1:1 dan 2:1 sebagai berikut:

Tabel 2. POLA BAGI HASIL.I

Table 2. Patern of Profit Sharing

\begin{tabular}{|ll|r|r|r|r|}
\hline & & Frequency & Percent & $\begin{array}{c}\text { Valid } \\
\text { Percent }\end{array}$ & $\begin{array}{c}\text { Cumulative } \\
\text { Percent }\end{array}$ \\
\hline Valid & GAJI & 38 & 48.7 & 48.7 & 48.7 \\
& $1: 1$ & 23 & 29.5 & 29.5 & 78.2 \\
$2: 1$ & 17 & 21.8 & 21.8 & 100.0 \\
& 78 & 100.0 & 100.0 & \\
\hline
\end{tabular}

Sumber/Source : Data Primer Diolah (2018)/Primary Data Processed (2018) 
Dari table diatas diketahui bahwa nelayan yang menerapkan system gaji ada sekitar 38 orang atau $48,7 \%$ dan nelayan yang menerapkan system bagi hasil 1:1 adalah sebanyak 23 orang atau sekitar $29,5 \%$ dan nelayan yang menerapkan system bagi hasil 2:1 sebanyak 17 orang atau sekitar $21,8 \%$. Dan dari data diatas dapat disimpulkan bahwa mayoritas nelayan di pulau pucung ini lebih banyak menggunakan pola bagi hasil dengan system gaji. Artinya bahwa mayoritas pemilik kelong tidak ikut melaut dan mengikutsertakan ABK dalam kegiatan melaut. Pembagian pola bagi hasil 1:1 dimana pemilik kelong tidak ikut melaut, kegiatan melaut diserahkan sepenuhnya kepada Tekong dan ABK, hal ini ditunjukkan dengan jumlah pembagian hasil toke yang sekaligus bertindak sebagai tekong dan nelayan sebanyak 23 orang. Dan yang paling sedikit yaitu dengan menggunakan pola bagi hasil 2:1 dimana toke ikutserta melaut dan dibantu oleh seorang tekong. Pola bagi hasil 1:1 dilaksanakan jika toke tidak ikut melaut, sementara pola bagi hasil 2:1 toke ikut melaut.

\section{Statistik Deskriptive}

Untuk melihat data yang digunakan dalam penelitian ini yaitu pola bagi hasil, tingkat kesejahteraan nelayan, lama bekerja, pendapatan/keuntungan rata-rata yang diperoleh nelayan dan pendidikan nelayan dilihat dari table descriptive statistic dibawah ini:

Tabel 4. Statistik Deskriptif.

Table 4. Descriptive Statistics.

\begin{tabular}{|l|r|r|r|r|r|}
\hline & \multicolumn{1}{|c|}{$\mathbf{N}$} & \multicolumn{1}{c|}{ Minimum } & \multicolumn{1}{c|}{ Maximum } & \multicolumn{1}{c|}{ Mean } & \multicolumn{1}{c|}{ Std. Deviation } \\
\hline POLA BAGI HASIL & 78 & 1.00 & 3.00 & 1.7308 & .80054 \\
LAMA BEKERJA & 78 & 1.00 & 38.00 & 9.4744 & 6.52811 \\
PENDAPATAN RATA- & 78 & $375,000.00$ & $7,500,000.00$ & $2,200,080.1282$ & $1,139,570.81626$ \\
RATA & & & & .81415 \\
PENDIDIKAN & 78 & 1.00 & 4.00 & 1.5769 & .82 \\
Valid N (listwise) & 78 & & & & \\
\hline
\end{tabular}

Sumber/Source : Data Primer Diolah SPSS 22/Primary Data Processed SPSS 22

Dari data diatas diperoleh informasi bahwa pola bagi hasil menunjukan nilai minimum 1 yaitu dengan system gaji, sementara nilai maksimum dengan angka 3 yaitu pola bagi hasil dengan system bagi hasil 2:1. Dan untuk lama bekerja nelayan paling sedikit 1 tahun dan paling lama 38 tahun bekerja sebagai nelayan. Dari table diatas keuntungan Pola Bagi Hasil antara Toke dengan Nelayan baik tekong atau ABK dengan jumlah keuntungan per bulan minimal $\mathrm{Rp}$. 375.000,- dan jumlah maksimal sebesar Rp.
7.500.000,- dan tingkat pendidikan mnimal 1 (SD) dan maksimum 4 (S1).

Penelitian yang dilakukan oleh (Tiara, 2016) tentang Sistem Bagi Hasil Nelayan Perikanan Tangkap di Pantai Indah Mukomuko, dimana hasil penelitiannya adalah Sistem bagi hasil yang diterapkan oleh nelayan Pantai Indah Mukomuko terbagi menjadi dua bentuk, yaitu bagi hasil $60 \%$ untuk nelayan pemilik dan $40 \%$ untuk nelayan penggarap, serta bagi hasil $50 \%$ untuk nelayan pemilik dan $50 \%$ untuk nelayan penggarap yang sudah sesuai dengan pembagian yang terdapat dalam 
UU Nomor 16 Tahun 1964 yaitu (50:50 dan $60: 40)$

\section{Kesimpulan}

Adapun kesimpulan yang dapat diambil dalam penelitian ini adalah :

Jumlah Responden dalam penelitian sebanyak 78 orang, dimana mayoritas responden berasal dari ABK yaitu sebanyak 48 orang.

Nelayan pulau pucung menerapkan 3 pola bagi hasil untuk kegiatan tangkap ikan dengan menggunakan kelong apung yaitu : System Gaji, 1:1 dan 2:1. Dan mayoritas menerapkan system Gaji kepada ABK.

Pendidikan nelayan mayoritas tamatan sekolah dasar.

Jumlah Keuntungan minimal yang diperoleh nelayan per bulan sebesar Rp. 375.000 dan maksimum Rp.7.500.000,-

\section{Implikasi Kebijakan}

Adapun implikasi kebijakan dalam penelitian ini adalah :

Bantuan pemerintah sangat diharapkan oleh nelayan kelong apalagi bagi nelayan yang belum mempunyai kelong seperti tekong dan anak buah kapal untuk meningkatkan pendapatan nelayan tersebut sehingga tingkat kesejahteraan nelayan bisa mengalami peningkatan khususnya nelayan kelong apung. Nelayan diharapkan bisa memperluas usaha kelong atau menambah jumlah kelong sehingga bisa meningkatkan pendapatan mereka. Untuk mengurangi ketergantungan dengan toke besar/tengkulak maka disarankan agar nelayan membentuk koperasi nelayan di Pulau Pucung desa Malang Rapat. Toke atau pemilik tekong telah menerapkan pola bagi hasil sesuai peraturan yang telah diterapkan oleh pemerintah.

\section{Ucapan Terima Kasih}

Penulis mengucapkan terima kasih kepada pihak-pihak yang terlibat dalam penelitian ini, baik dari pihak perguruan tinggi sebagai penyedia dana penelitian ini yaitu Rektor Univ. Maritim Raja Ali Haji. Penulis juga mengucapkan terima kasih kepada Ketua LPPPM, Dekan Fakultas Ekonomi Universitas Maritim Raja Ali Haji, Sekretaris Desa beserta jajarannya, ketua kelompok nelayan dan nelayan kelong apung Pulau Pucung serta mahasiswa yang membantu dalam penyebaran kuesioner dan pengumpulan data pada penelitian ini. Semoga hasil penelitian ini bisa memberikan kontribusi kepada Universitas sebagai perwujudan untuk mencapai visi dan misi universitas yaitu menjadi pusat unggulan riset maritim, sebagai bahan masukan kepada pemerintah daerah terkait factor penentu kesejahteraan nelayan kelong apung.

\section{Daftar Pustaka}

(BKKBN) Badan Koordinasi Keluarga Berencana Nasional 2014

Evers, S. (1982). Kemiskinan dan Kebutuhan Pokok. Jakarta: CV. Rajawali.

Fahrudin, A. (2012). Pengantar Kesejahteraan Sosial. Bandung: Refika Aditama.

Irawan, B., \& Suryana, A. (n.d.). Sistem bagi hasil dan dampak motorisasi penangkapan ikan terhadap pendapatan nelayan di langkat sumatera utara.

Kusnadi. (2002). Keberadaan Nelayan dan Dinamika Ekonomi Pesisir. Jogyakarta: Ar-Ruzz Media.

Marbun, L. \& I. N. K. (2002). Masyarakat Pinggiran Yang Kian Terlupakan. Medan: Jala Kompalindo.

Prihantini, C. I., Syaukat, Y., \& Fariyanti, A. (2017). Perbandingan Keuntungan Dengan Sistem Bagi Hasil Pada Usaha Garam Rakyat di Kabupaten Pamekasan, Jawa Timur. Jurnal Sosial Ekonomi Kelautan Dan Perikanan, 12(1), 63-76. 
FE Universitas Maritim Raja Ali Haji

Rosni. (2012). Anlisis Tingkat Kesejahteraan Masyarakat Nelayan Di desa Dahari Selebar Kecamatan Talawi Kabupaten Batubara. Jurnal Geografi, (2002), 53-66. https://doi.org/6038-11930-1-SM.pdf

Scheltema, A.M.P.A. (1985). Bagi Hasil di Hindia Belanda. Jakarta (ID): Yayasan Obor Indonesia

Subri. (2005). Ekonomi Kelautan. Jakarta: Raja Grafindo Persada.

Tiara, I. D. (2016). Sistem Bagi Hasil Nelayan Perikanan Tangkap di Pantai Indah MukoMuko. Bogor. 